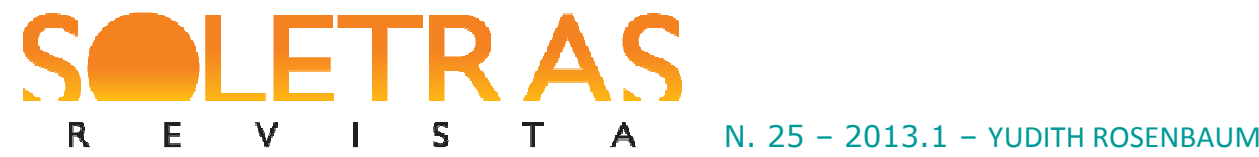

\title{
Manuel Bandeira: o poeta da reconstrução
}

Yudith Rosenbaum ${ }^{1}$

Resumo: O ensaio se propõe a analisar o poema "Gesso", de Manuel Bandeira, compreendendo-o como matriz poética de uma atitude reparadora frente à destruição dos objetos do mundo interior e exterior. Ao lado do instrumental da estilística, convocou-se a abordagem psicanalítica kleiniana para ampliação de significações do poema e da trajetória maior do poeta e de sua obra.

Palavras-chave: Manuel Bandeira. Melanie Klein. Poesia. Reparação.

O poema "Gesso", que integra o volume O ritmo dissoluto, de 1924, pode ser visto como uma condensação de algumas vertentes da poética de Manuel Bandeira. Pretende-se, aqui, abordá-lo justamente como uma chave compreensiva de aspectos centrais do poeta pernambucano, visto na amplitude de sua trajetória biográfica e literária.

Já se sabe, pelo testemunho do próprio poeta em Itinerário de Pasárgada, de 1954, como enfrentou as mazelas de seu destino a partir de uma entrega absoluta ao fazer poético. Dos versos de desabafo aos dezoito anos, quando acometido pela tuberculose em 1904, ao domínio consciente e abrangente da poesia ao longo de quase 70 anos de atividade, Manuel Bandeira combateu as perdas de toda ordem, financeiras e afetivas, sustentado pelo exercício poético como consolo e forma de conhecimento de si e do mundo. Desse modo, cada conquista de mais um dia de vida representava a vitória de um homem sobre a fatalidade anunciada.

Sob essa perspectiva, o poema "Gesso" pode iluminar o processo pelo qual o homem e o poeta se encontram, fazendo do "mau destino" uma travessia de sabedoria: ${ }^{2}$

\footnotetext{
Gesso

Esta minha estatuazinha de gesso, quando nova

- O gesso muito banco, as linhas muito puras, -

Mal sugeria a imagem de vida

(Embora a figura chorasse).

Há muitos anos tenho-a comigo.
}

\footnotetext{
${ }^{1}$ Yudith Rosenbaum é professora de Literatura Brasileira na Universidade de São Paulo (USP). Publicou os livros Manuel Bandeira: uma poesia da ausência (EDUSP, 2002); Metamorfoses do mal: uma leitura de Clarice Lispector (EDUSP, 1999); Clarice Lispector (Publifolha, 2002, Coleção Folha Explica) e O livro do psicólogo (Companhia das Letrinhas, 2004).

${ }^{2}$ Refiro-me aos versos de abertura do poema "Epígrafe", de Cinza das horas, de 1912: "Sou bem nascido. Menino / Fui como os demais, feliz. / Depois veio o mau destino / E fez de mim o que quis" (BANDEIRA, 1986, p. 193). As citações serão sempre desta edição.
} 
O tempo envelheceu-a, carcomeu-a, manchou-a de pátina amarelo-suja.

Os meus olhos, de tanto a olharem,

Impregnaram-na da minha humanidade irônica de tísico.

Um dia mão estúpida

Inadvertidamente a derrubou e partiu.

Então ajoelhei com raiva, recolhi aqueles tristes fragmentos, recompus a

[figurinha que chorava.

E o tempo sobre as feridas escureceu ainda mais o sujo mordente da pátina...

Hoje este gessozinho comercial

É tocante e vive, e me fez agora refletir

Que só é verdadeiramente vivo o que já sofreu.

Uma visada rápida pelos versos não deixa dúvida de que se trata daquela poesia que podia nascer "tanto dos amores quanto dos chinelos", 3 ou seja, poesia nascida de objetos os mais triviais e simplórios, como um gesso comercial. A operação poética que desentranha do mais humilde cotidiano uma sublime experiência, conforme estudou em profundidade o crítico Davi Arrigucci Jr (1993), ressurge aqui na forma de uma reconstrução dos fragmentos de uma peça de gesso quebrada. É sobre o fundo simbólico deste gesto que pretendo comentar o caminho desse singular poema narrativo.

Após um livro como Cinza das horas, que tematiza a dor do doente na mescla de formas penumbristas e crepusculares - ao lado de ousadias modernistas -, e Carnaval (1919), volume que tenta a expansão contida no livro anterior (mas que só alcança um "carnaval sem nenhuma alegria") ${ }^{4}$, a terceira coletânea, $O$ ritmo dissoluto, é vista pelo próprio poeta como passagem ou transição para formas mais libertas, que serão consolidadas em Libertinagem, de $1930^{5}$. E é nesta travessia em direção à libertação do poeta que se insere o poema em foco, contendo, portanto, uma poética implícita a ser demonstrada pela análise.

O tratamento no diminutivo ("estatuazinha", "figurinha", "gessozinho") marca o poema em seus momentos essenciais e já delineia a posição subjetiva do eu-lírico ao relatar o

\footnotetext{
${ }^{3}$ Cf. Bandeira, 1954, p. 11: "Assim, na companhia paterna ia-me embebendo dessa ideia de que a poesia está em tudo - tanto nos amores como nos chinelos, tanto nas coisas lógicas como nas disparatadas".

${ }^{4}$ Conforme o último verso do poema "Epílogo" (BANDEIRA, 1986, p. 178).

5 "A mim me parece bastante evidente que $O$ ritmo dissoluto é um livro de transição entre dois momentos da minha poesia. Transição para quê? Para a afinação poética dentro da qual cheguei, tanto no verso-livre como nos versos metrificados e rimados, isso do ponto de vista da forma; e na expressão das minhas ideias e dos meus sentimentos, do ponto de vista do fundo à completa liberdade de movimentos, liberdade de que cheguei a abusar no livro seguinte, a que por isso mesmo chamei Libertinagem" (BANDEIRA, 1986, p. 71). 
acontecimento em que, acidentalmente, estilhaça a peça que traz tantos anos consigo. É um eu-infantil que abre o relato e o acompanha da perspectiva de uma criança, a mesma que teima em não crescer, no poema "Versos de Natal”, de Lira dos Cinquent'anos ${ }^{6}$. No início, o gesso quando novo "mal sugeria a imagem de vida / (embora a figura chorasse)". O gesso é branco e as linhas muito puras, o que remete a uma imagem imaculada. O choro, marca de uma dor, existe - mesmo que entre parênteses -, mas não imprime vida à estatuazinha. Constrói-se uma atmosfera de um objeto ainda preservado de qualquer contato com um mundo destruidor. A vida não pulsa neste ser inanimado e o choro da escultura é ainda um reflexo sem humanidade. Mas “o tempo envelheceu-a, carcomeu-a, manchou-a de pátina amarelo-suja", diz o verso da primeira estrofe. A história e a experiência humana são implacáveis, como se vê na sequência dos verbos no pretérito perfeito. $\mathrm{O}$ aspecto de duração prolongada, que marcou até aqui a estrofe pelo uso do imperfeito ("sugeria"), agora desaparece para dar lugar à força imperativa da passagem definitiva do tempo.

As inscrições da temporalidade, que maculam a pureza do gesso, estendem-se pela segunda estrofe, acrescidas pela impregnação do olhar do poeta e sua "humanidade irônica de tísico". Chama atenção a projeção da interioridade do sujeito no objeto, sobretudo de sua condição de doente, para quem a vida já deixou de ter a pureza alva ("o gesso muito branco", "as linhas muito puras"), como na juventude (quando era "nova"). Essa ideia de que a subjetividade se derrama sobre o entorno, dando a ele um caráter humano, revela muito da visão poética bandeiriana. Movimentando-se pouco e ousando menos ainda em função das limitações impostas pela doença, o poeta faz vibrar o mundo de acordo com as suas vivências mais fundas. É assim que entendo a estrofe final do poema "Estrada", do mesmo livro em que está "Gesso":

\section{$[\ldots]$}

Nem falta o murmúrio da água, para sugerir pela voz dos símbolos, Que a vida passa! que a vida passa!

E que a mocidade vai acabar (BANDEIRA, 1986).

A vida que passa no interior do poeta se derrama toda no murmúrio da água, cujo som se impregna da sua humanidade finita. Exterior e interior parecem amalgamar-se de modo singular. A expressão da finitude da vida encontra eco na fugacidade da água. No verso do

\footnotetext{
${ }^{6} \mathrm{Na}$ segunda estrofe, lê-se: "Mas se fosses mágico / Penetrarias até o fundo desse homem triste, / Descobririas o menino que sustenta esse homem, / O menino que não quer morrer, / Que não morrerá senão comigo" (BANDEIRA, 1986, p 251).
} 


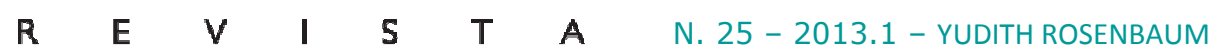

poema "O espelho", também de $O$ ritmo dissoluto, nota-se a mesma dinâmica: "Ardo em desejo na tarde que arde!".

Para além das ressonâncias simbolistas ou crepusculares, algo maior parece tomar forma, ganhando expressividade no poema "Gesso". A convivência do poeta com seus objetos, com os elementos miúdos de seu habitat, transforma a matéria inerte, dando a ela uma dimensão de vida. Talvez a poesia seja a própria metamorfose em jogo, já que nela o sujeito é capaz de construir-se enquanto nomeia e humaniza o mundo. Como no verso: "a arte é uma fada que transmuta / E transfigura o mau destino" "7. Para reforçar a ideia, lembremos dos versos de "Última canção do beco", de Lira dos Cinquent'anos, em que o "Beco das minhas tristezas, / Das minhas perplexidades" - notemos o possessivo ("minhas") sugerindo a identificação entre sujeito e objeto - é o espaço do encontro absoluto do homem consigo mesmo. Tanto é assim que a segunda estrofe, ao referir-se à possível demolição do lugar de moradia no beco, faz persistir o quarto do poeta como uma espécie de "imaterialidade concreta”, detentor de uma presença material mesmo na inexistência:

\section{$[\ldots]$}

Vão demolir esta casa.

Mas meu quarto vai ficar.

Não como forma imperfeita

Neste mundo de aparências:

Vai ficar na eternidade,

Com seus livros, com seus quadros,

Intacto, suspenso no ar! (BANDEIRA, 1986).

$[\ldots]$

De novo, a demolição é seguida de uma restauração, ainda que "na eternidade" do espaço poético. E também aqui, como no poema "Gesso", os objetos se autonomizam, se humanizam, pela força que o sujeito lírico imprime a eles, dada a intensa comunhão entre ambos. Na verdade, nos dois textos algo é destruído (como se verá nos próximos versos de "Gesso") e a atitude lírica se volta para um modo de remodelar ou reconstruir o vivido, buscando superar a inevitabilidade de sua destruição.

A estrofe seguinte se inicia com uma locução temporal, expediente bastante utilizado pelo poeta, intensificando o aspecto narrativo do poema:

Um dia mão estúpida

Inadvertidamente a derrubou e partiu (BANDEIRA, 1986).

\footnotetext{
${ }^{7}$ Verso do poema “À sombra das araucárias”, de Cinza das horas.

SOLETRAS - Revista do Departamento de Letras da FFP/UERJ

Número 25 (jan.-jun. 2013)

ISSN: 2316-8838
} 
Curioso notar como o relato da "cena traumática" (expressão que uso aqui consciente de suas repercussões psicanalíticas) é feito de forma sintética e objetiva, sem detalhes desnecessários ou supérfluos. Nada desfoca o cerne do acidente e a sonoridade das oclusivas e bilabiais (/d/, /t/, /p/) marcam a força do golpe. A "mão estúpida" é o agente da queda, como se o sujeito transferisse para uma parte de seu corpo - e não a si mesmo - a responsabilidade da ação desastrada. E a atacasse ("estúpida") para tentar, ainda, eximir-se do gesto. Mas, o advérbio - "inadvertidamente" - impede qualquer julgamento e atribui o incidente ao acaso. Coexistem ataque e conciliação nos mesmos versos. Imprevisto e responsabilidade se confundem. O fato é que algo é derrubado e partido, sinal inequívoco do "mau destino", em um plano biográfico, e de todas as intempéries inadvertidas da vida, capazes de ferir a inocência e a inteireza do ser. Tantas vezes esse emblema da fatalidade se coloca na poesia de Bandeira que seria preciso um novo ensaio para comentá-la. Mas bastaria retomar o cacto tombado por um tufão, no poema "O cacto", Note-se, ainda, a repetição, no primeiro verso, da indicação temporal, "um dia", signo da imprevisível catástrofe que ronda o sujeito lírico - ou dos fenômenos naturais que a ele se referem:

$$
[\ldots]
$$

Um dia um tufão furibundo abateu-o pela raiz.

$\mathrm{O}$ cacto tombou atravessado na rua

Quebrou os beirais do casario fronteiro,

Impediu o trânsito de bondes, automóveis, carroças,

Arrebentou os cabos elétricos e durante vinte e quatro horas privou a cidade [de iluminação e energia:

Era belo, áspero, intratável.

\footnotetext{
${ }^{8}$ O poema está no volume Libertinagem (BANDEIRA, 1986, p. 206). Vale a pena reproduzi-lo na íntegra:
}

Aquele cacto lembrava os gestos desesperados da estatuária:

Laocoonte constrangido pelas serpentes,

Ugolino e os filhos esfaimados.

Evocava também o seco nordeste, carnaubais, caatingas...

Era enorme, mesmo para esta terra de feracidades excepcionais.

Um dia um tufão furibundo abateu-o pela raiz.

$\mathrm{O}$ cacto tombou atravessado na rua.

Quebrou ou beirais do casario fronteiro.

Impediu o trânsito de bonde, automóveis, carroças,

Arrebentou os cabos elétricos e durante vinte e quatro horas privou a cidade de iluminação e energia:

- Era belo, áspero, intratável.

SOLETRAS - Revista do Departamento de Letras da FFP/UERJ

Número 25 (jan.-jun. 2013)

ISSN: 2316-8838 
Neste caso, o tufão é o agente da desgraça, enquanto no poema "Gesso" é o próprio poeta que assume a causa da queda da estatueta, ainda que "inadvertidamente". Mas sendo ela - a estatuazinha - também a metáfora do sujeito lírico abatido pelo tempo (e pela doença), o leitor compreende que se trata da própria fragilidade da existência, à mercê de tantos reveses e obstáculos.

O que vem a seguir resgata a potência de quem "tombou", mas sabe resistir ao golpe:

Então ajoelhei com raiva, recolhi aqueles tristes fragmentos, recompus a E o tempo sobre as feridas escureceu ainda mais o sujo mordente da pátina...

O crítico Murilo Marcondes de Moura (2001, p. 38) notou bem o paradoxo da cena: "[...] a expressão "ajoelhei com raiva" é quase um oxímoro, ao indicar, simultaneamente, humilhação e atuação forte. A construção paradoxal tem aqui enorme precisão, pois abrange tanto a situação do eu submetido à devastação do tempo, como também sua capacidade de recompor as perdas numa integridade que lhe é própria”. De fato, o gesto é ambíguo e carrega a dupla sensação: por um lado, a necessidade de curvar-se (ajoelhar-se) ao inevitável; por outro, a face agressiva que caminha junto com a aceitação. Talvez não seja propriamente um ressentimento frente à adversidade. Como observou Alcides Villaça, "incorporar a experiência do sofrimento com aquele sinal positivo que também lhe deu Mário de Andrade de 'a própria dor é uma felicidade' não é curvar-se ao fatalismo, mas sobreviver a ele e contestá-lo com a experiência mesma do poético, objetivada em palavras” (VILLAÇA, 1987). Em Bandeira, haveria antes um reconhecimento de que a vida tem uma autonomia desconcertante e que é preciso:

Ser como o rio que deflui

Silencioso dentro da noite.

Não temer as trevas da noite.

Se há estrelas nos céus, refleti-las.

E se os céus se pejam de nuvens,

Como o rio as nuvens são água,

Refleti-las também sem mágoa

Nas profundidades tranqüilas (BANDEIRA, 1986).

O poema "O rio" (de Belo Belo), acima citado, é a cifra de uma aprendizagem fundamental. A natureza ensina ao poeta tanto quanto um gesso estilhaçado. O plano baixo do 


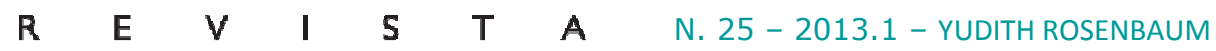

rio e o plano alto das estrelas e das nuvens se equivalem, diz o poema. E quando "os céus se pejam de nuvens", não há nada a temer, pois as nuvens são água como o rio. "Sem mágoa" e "nas profundidades tranquilas" são expressões que contrastam com a raiva do poeta ao reunir os pedaços do gesso, mas, em ambos os textos, ressoa a operação poética, capaz de reverter a ruína em obra. Em "O rio", a ideia de "refletir" parece referir-se ao ato da mimese artística, enquanto em "Gesso" as palavras "recolher" e "recompor" são, certamente, atitudes afirmativas e revelam a força construtiva da poesia.

Talvez aqui fosse interessante uma visada extraliterária a partir de algumas noções da psicanálise, sobretudo a kleiniana, de modo a ampliar as significações do poema. Remontar os destroços do desastre remete-nos ao que a teoria de Melanie Klein (1996) interpretava como um ato de reparação da destruição que o próprio sujeito infligia aos objetos frustrantes do mundo em seu universo íntimo. Nas vivências mais precoces, segundo os teóricos kleinianos, o bebê não é capaz de integrar em si os elementos negativos que o assolam, sejam do seu interior, sejam da exterioridade. Na verdade, não é possível ainda discriminar o que está dentro de si do que está fora, como a figura materna e os demais estímulos que afetam o sujeito. Aliás, o seio amamentador é vivido como uma entidade absoluta, ainda não percebida como uma parte do todo.$^{9}$

Os processos defensivos da cisão em objeto bom e objeto mau, diz ainda Klein, visam proteger o infante das emoções destrutivas, projetando o mal para fora de si e se identificando apenas com seus aspectos bons. Melanie Klein denominou este momento do desenvolvimento infantil de fase "esquizo-paranoide", justamente pela impossibilidade de integrar aspectos opostos no mesmo objeto, vivendo uma polarização de partes inconciliáveis. A idealização do objeto amado e a fantasia de que este é um provedor absoluto acompanham esse estádio e fazem parte de um percurso normal de subjetivação. A maturação advinda com o crescimento propicia nessa etapa uma nova operação fundamental: o sujeito percebe que destruiu o que também constituía os objetos gratificantes (a mãe que frustra, e por isso é atacada, é a mesma

\footnotetext{
9 "Na posição esquizo-paranóide, a ansiedade predominante é a de que o objeto ou objetos perseguidores entrarão no ego e dominarão e aniquilarão tanto o objeto ideal quanto o eu (self), que contém o instinto de morte. Essas características da ansiedade e das relações de objeto experimentadas durante essa fase levaram Melanie Klein a chamá-la de "posição esquizo-paranoide", já que a ansiedade predominante é paranoide e já que o estado do ego e de seus objetos é caracterizado pela divisão (splitting) que é esquizoide" (Cf. SEGAL, 1975, p. 38).
} 
que alimenta e gera prazer). Tal vivência é produtora de culpa e angústia, o que leva à fase seguinte, denominada "depressiva".

É neste processo que a noção de um objeto total pode ser construída, fazendo com que a mãe e o indivíduo sejam reconhecidos como seres inteiros: "a integração do ego e do objeto ocorre simultaneamente" (SEGAL, 1975, p. 82). Mas a travessia para a integração implica a percepção de que o objeto amado foi destruído por impulsos agressivos (podendo colocar-se como ameaçador e perseguidor na fantasia infantil) e que a restauração é um esforço amoroso frente ao que foi devastado:

A experiência de depressão mobiliza no bebê o desejo de reparar seu objeto ou seus objetos destruídos. Anseia por compensar o dano que infligiu a eles em sua fantasia onipotente, por restaurar e recuperar seus objetos amados perdidos, e por lhes dar de volta vida e integridade. Acreditando que seus próprios ataques destrutivos foram responsáveis pela destruição do objeto, acredita também que seu próprio amor e seu próprio cuidado podem desfazer os efeitos de sua agressividade. O conflito depressivo é uma luta constante entre a destrutividade do bebê e seu amor e impulsos reparadores (SEGAL, 1975, p. 85).

Frente a essa pequena síntese de algumas noções kleinianas, podemos retornar ao poema e tentar pensar para onde pode nos levar essa incursão na teoria psicanalítica, em princípio tão distante de nosso poeta.

Deixamos o poema no momento em que o poeta recolhia com raiva e devoção os fragmentos dispersos do gesso quebrado (referido então como "a figurinha que chorava", sendo agora um choro mais sentido do que na estrofe anterior). Pela identificação erigida pelos versos entre o sujeito lírico e a estatuazinha, pudemos ampliar a ideia de um mau destino que teria abatido o poeta e pensar o desastre pelo viés autodestrutivo. A si mesmo também a "mão estúpida" golpeou. Um paralelo com o poema "Contrição", de Estrela da Manhã (1936) pode reforçar essa dimensão, já que nele o poeta se desespera ao reconhecer-se impuro, tendo descido ao mais baixo patamar da existência e se autoagredido:

Quero banhar-me nas águas límpidas

Quero banhar-me nas águas puras

Sou a mais baixa das criaturas Me sinto sórdido

Confiei às feras as minhas lágrimas

Rolei de borco pelas calçadas

Cobri meu rosto de bofetadas 
Meu Deus valei-me

Vozes da infância contai a história

Da vida boa que nunca veio

E eu caia ouvindo-a no calmo seio

Da eternidade (BANDEIRA, 1986)

As imagens negativas se acumulam no poema ("sou a mais baixa das criaturas", "rolei de borco pelas calçadas", "cobri meu rosto de bofetadas") e trazem um poeta aflito, que só se apazigua na última estrofe. Até lá são versos em que o eu-lírico penitencia-se de uma vida degradada. A destruição que vimos no poema "Gesso" desloca-se aqui inteiramente para a própria pessoa do poeta. Mas, novamente um processo reparador se põe em movimento e aciona as "vozes da infância" para contarem "a história da vida boa que nunca veio" - como a "vida inteira que podia ter sido e que não foi", do conhecido poema "Pneumotórax", do livro Libertinagem. É essa reversão que permite ao crítico Murilo Marcondes de Moura afirmar que o impulso autodestrutivo "aparece envolto por uma expressão calma, que é, na verdade, o maior contraste do poema" (MOURA, 2001, p. 58).

A visada que se abre aqui - a face de um poeta mais raivoso, mais agressivo com a vida e consigo mesmo - encontra o seu contraponto na atividade artística, verdadeira poiesis redentora das agruras e pulsões destrutivas. Em "Contrição", são as narrativas da infância que conseguem trazer a calmaria ao poeta decaído; já no poema "Infância" (Belo Belo), uma vertiginosa corrente de versos que relembram a infância, evocada na dispersão fragmentária, ganha uma unidade pela força da poesia restauradora e que por isso mesmo surge como "poesia dos naufrágios". Novamente, aqui a catástrofe dos pedaços soltos de uma existência atravessada pelo "mau destino" conhece o seu momento restaurador.

Da mesma linhagem é o poema "O martelo", de Lira dos Cinquent'anos (BANDEIRA, 1986), cujos versos centrais apontam para a mesma questão:

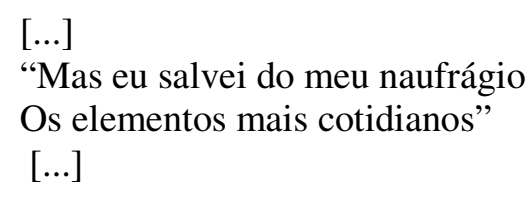

O poeta náufrago é, certamente, um topos singular da obra bandeiriana e se articula muito com o que analisamos aqui. Há uma oscilação perene entre destruição e reconstrução, trazendo o acento para o movimento de reparação e colagem dos fragmentos e destroços da existência. Entre a relação com os objetos ideais (o gesso imaculado), passando por ataques 
destruidores seguidos de uma reunião integradora, há um lento processo de maturação onde o tempo é seu agente.

Tendo sido ferido pela vida e por si mesmo, o poeta reconhece, no final do poema central deste percurso, que o sofrimento traz uma nova vitalidade, um sentimento verdadeiro de estar vivo:

Hoje este gessozinho comercial

É tocante e vive, e me fez agora refletir

Que só é verdadeiramente vivo o que já sofreu (BANDEIRA, 1986).

Note-se o jogo de tempos verbais plasmando o contraste entre o que é e está vivo no presente e o que já sofreu no passado: o hoje e o agora trazem a reflexão definitiva do poeta, já que ele não se fixou à imagem ideal perdida. O que vale é a sua superação. A queda, o sofrimento, a destruição não se perdem como pura fatalidade. Eles se transformam em "verdadeiramente vivo" porque real. É o gesto reconstrutor do poeta, para além de um consolo conformista, que faz a diferença entre a melancolia da perda e o luto da elaboração ${ }^{10}$. Mas para isso é preciso recolher do solo o que foi destruído e acreditar na sua recuperação ou recomposição. A capacidade reparadora é, como nos mostra Bandeira, matriz da atividade criadora. E a poesia, essa cinza das horas, é expressão desse embate entre o que resta e o que revive pela reconstrução.

\section{Referências bibliográficas:}

BANDEIRA, Manuel. Poesia completa e prosa. Rio de Janeiro: Nova Aguilar, 1986.

. Itinerário de Pasárgada. Rio de Janeiro: Edições Jornal de Letras, 1954.

KLEIN, Melanie. Amor, culpa e reparação e outros trabalhos. Rio de janeiro: Imago, 1996

JR, ARRIGUCCI, Davi. Manuel Bandeira: humildade, paixão e morte. São Paulo: Companhia das Letras, 1993.

MOURA, Murilo Marcondes de. Manuel Bandeira. São Paulo: Publifolha, 2001 (Série Folha Explica).

ROSENBAUM, Yudith. Manuel Bandeira: uma poesia da ausência. 2. ed. São Paulo: EDUSP, 2002.

\footnotetext{
${ }^{10}$ A esse respeito, reenvio os leitores ao meu estudo sobre a passagem da melancolia ao luto pela poesia, em Rosenbaum (2002).
} 
SEGAL, Hanna. Introdução à obra de Melanie Klein. Rio de Janeiro: Imago Editora, 1975.

VILLAÇA, Alcides. O resgate íntimo de Manuel Bandeira. In: LOPEZ, Telê Ancona (Org.). Manuel Bandeira: verso e reverso. São Paulo: T.A. Queiroz Editor, 1987.

\title{
Manuel Bandeira: the poet of reconstruction
}

\begin{abstract}
The essay is a study on the põem "Gesso", by Manuel Bandeira, here understood as a poetic matrix of an attitude of recovery when facing the destruction of the objects of the inner and outside worlds. Side by side with stylistics as a reading tool, the kleinian psychoanalitical approach will amplify the scope of meanings of the poem "Gesso" as well as the undesrtandin of the poetic journey emprehended by Bandeira in his poetic works.
\end{abstract}

Key words: Manuel Bandeira. Melanie Klein. Poetry. Recovery.

Recebido em: 03 de junho de 2013.

Aprovado em: 13 de junho de 2013. 